\title{
O NÚCLEO ESSENCIAL DOS DIREITOS FUNDAMENTAIS E O SISTEMA CARCERÁRIO BRASILEIRO
}

\author{
Savio Guimarães Rodrigues ${ }^{1}$
}

\section{RESUMO}

O presente estudo pretende promover o debate acerca do sistema carcerário brasileiro sob a óptica da eficácia dos direitos fundamentais dos presos. Argumenta-se que as restrições aos direitos fundamentais inseridas num âmbito de relações especiais de sujeição encontram, elas próprias, limites diante do conteúdo essencial da dignidade humana. Por certo, a situação atual do sistema encerra argumentos contramajoritários que, preponderantes, sustentam direitos públicos às prestações positivas do Estado, independentemente da disponibilidade de recursos destinados especificamente à política carcerária. Não há que se falar em reserva do possível quando está em jogo o núcleo essencial da dignidade daqueles a quem o próprio Estado, ao limitar a liberdade inerente ao ser humano, assume os deveres inafastáveis da tutela.

Palavras-Chave: direitos fundamentais; núcleo essencial da dignidade humana; sistema carcerário; reserva do possível; direitos públicos subjetivos.

\section{THE ESSENTIAL CORE OF FUNDAMENTAL RIGHTS AND THE BRAZILIAN PENITENTIARY SYSTEM}

\begin{abstract}
This study pretends to promote the debate about the Brazilian prison system from the perspective of the effectiveness of prisoners' fundamental rights. It is argued that restrictions on fundamental rights are, in the context of special relations between individuals and State, limited in face of the essence of human dignity. Certainly, the current system carries specific arguments that sustain public rights to positive benefits, regardless of the availability of resources devoted

\footnotetext{
${ }^{1}$ Mestrando em Direito Penal pela Universidade do Estado do Rio de Janeiro, UERJ. E-mail: savio.gr@hotmail.com
} 
specifically to prison policy. We should not speak of materials possibilities when is in risk the dignity of those whom the State itself, by restricting the freedom inherent in human beings, assumes the duties of guardianship.

Keywords: fundamental rights; essential core of fundamental rights; prison system; reserve of possibility; subjective public rights.

\section{INTRODUÇÃO}

Muito se tem escrito no Brasil, notadamente nas últimas duas décadas, sobre a eficácia e a centralidade dos direitos fundamentais, consensos mínimos erigidos a fundamentos do ordenamento jurídico. De fato, diante da Carta de 1988 e seu extenso rol de objetivos estatais, direitos e garantias individuais e coletivos, reflexo da tentativa de superação de um regime opressivo anterior $^{2}$, a dignidade humana assume a posição de fim último legitimador de toda a ordem jurídica (CASTRO, 2006, p. 135/179).

Diante disso, era de se esperar que atuação do Estado se pautasse, seja qual fosse o caso, no sentido da promoção dos direitos humanos, ora protegendo os direitos individuais de liberdade dos cidadãos ora promovendo (positivamente) seus direitos de igualdade.

Ocorre que, dentre os inúmeros paradoxos brasileiros um se revela especialmente preocupante: por um lado, o país é signatário dos principais pactos internacionais sobre Direitos Humanos, vem adotando nos últimos anos diversos programas voltados à promoção do tema (o Programa Nacional de Direitos Humanos 3, do Governo Federal, é um exemplo disto) e vivencia a constitucionalização do Direito e o reconhecimento da normatividade e da centralidade dos direitos fundamentais; por outro, a situação atual (mas não nova) de grande parte de seus estabelecimentos prisionais é estarrecedora, exemplo de um tratamento desumano e degradante institucionalizado.

É fato notório desde há muito que as condições encontradas em grande parte ${ }^{3}$ dos presídios brasileiros denotam um descaso do Poder Público, uma omissão estatal de gravidade

\footnotetext{
${ }^{2}$ O que a coloca em meio à grande parte das constituições ocidentais contemporâneas, principalmente no período pós-segunda guerra mundial.

${ }^{3}$ Mas não em todos, é bom que se diga para evitar generalizações.
} 
tamanha que nos leva a repensar a consciência que nossa sociedade possui da dimensão dos direitos fundamentais, principalmente da igualdade dos homens em dignidade (BARCELLOS, 2010).

Assim, propõe-se aqui uma releitura do sistema carcerário brasileiro sob a óptica da eficácia dos direitos fundamentais dos presos, em especial aquela decorrente das condições mínimas para uma existência digna, com vistas a construir ao menos uma possibilidade de resposta ágil a um problema tão urgente como este que se apresenta.

Para isso, procura-se delimitar a estrutura normativa dos direitos fundamentais diante das relações especiais de sujeição, evidenciando a partir daí a configuração de um estatuto jurídico especial dos reclusos que lhes garanta direitos públicos subjetivos em face do Estado.

Nesse sentido, tem-se que as restrições aos direitos fundamentais inseridas naquele âmbito de relações especiais de sujeição conformam, elas próprias, os contornos de um conteúdo mínimo de dignidade, resultado do jogo de ponderação que conformou as balizas daquelas restrições.

Em que pese à constitucionalidade e a necessidade do regime prisional, em si mesmo uma restrição imposta aos direitos fundamentais do indivíduo, fato é que as condições concretas sob as quais vivem os prisioneiros brasileiros ultrapassam, em muito, os parâmetros legais e constitucionais razoáveis da restrição à liberdade, consubstanciando o descaso estatal verdadeira violação ao núcleo da dignidade humana, sem que se possa vislumbrar uma argumentação racional de cunho constitucional a lhe prestar suporte.

Afinal, não se pode esquecer que os condenados a penas privativas de liberdade, embora tenham visto seus direitos tolhidos diante de interesses coletivos julgados superiores no caso concreto, não deixam de ser humanos, não deixam de possuir direitos mínimos inerentes a sua personalidade. Pelo contrário, o status peculiar em que se encontram (de tutelados em prol de uma suposta promessa de ressocialização ${ }^{4}$ ) deveria conferir a estes pretensões específicas em face do Estado, por vezes até mais fortes que aquelas ostentadas pelos cidadãos comuns,

\footnotetext{
${ }^{4}$ Hoje ganha força o pensamento segundo o qual competiria ao regime prisional mais evitar uma dessocialização do que propriamente promover uma socialização. Parte-se da incoerência que é a pretensão de se imputar uma certa pauta de comportamentos sociais com o isolamento do convívio social. Nesse sentido: RODRIGUES, 2002, pp. $143 / 175$.
} 
relacionadas (principalmente, mas não só) à garantia da vida, da integridade física, e da saúde dentro da instituição carcerária.

Para que o detento deixe, enfim, de ser objeto de direito numa relação de poder em face da Administração Pública, submetido à discricionariedade administrativa, e passe a ser sujeito de direitos, é imperioso reconhecer um estatuto jurídico pessoal em conjunto com o progressivo e efetivo controle jurisdicional da execução penal.

\section{A TEORIA: A ESTRUTURA NORMATIVA E O NÚCLEO ESSENCIAL DOS DIREITOS FUNDAMENTAIS}

Antes de adentrar ao tema proposto, faz-se necessário o estabelecimento de algumas premissas teóricas acerca dos direitos fundamentais que prestarão suporte a todas as outras construções argumentativas realizadas ao longo do texto. Nesta primeira parte, portanto, tentase lançar a base teórica sobre a qual se analisará, mais adiante, a realidade brasileira.

Muito se tem falado no Brasil sobre direitos fundamentais. O tema em si já envolve uma série de implicações e atrai consigo uma infinidade de teorias e discussões. São os direitos fundamentais universalizáveis? Decorrem das Constituições ou são a ela anteriores? Possuem eficácia direta? Podem ser aplicados em relações privadas? Ou são reservados aos indivíduos em sua interface com o Estado?

Muito embora o tratamento dessas questões transborde os limites do presente trabalho, alguns apontamentos dogmáticos devem aqui ser tratados. O primeiro deles é o reconhecimento dos direitos fundamentais como normas jurídicas em seu sentido clássico (HESSE, 1991), não no retórico ou meramente argumentativo.

Como toda norma jurídica, os direitos fundamentais são preceitos que buscam, por meio da direção de comportamentos humanos, a alteração ou conformação da realidade fática, gozando, para isso, de imperatividade. São, portanto, enunciados deônticos, pelos qual se expressa um dever-ser.

A norma, é bom distinguir de logo, não se confunde com o texto legal. O que vemos, por exemplo, nos incisos do artigo $5^{\circ}$ da Constituição Federal são a princípio textos. Preceitos lingüísticos. Será a partir deste elenco que procuraremos depreender as normas a serem aqui analisadas. 
Isso porque a norma é o resultado da construção (ou reconstrução como quer ÁVILA 2006, pp. 30/35) de sentido promovida pela interpretação do texto. O texto é o objeto de interpretação enquanto a norma é o seu resultado. Veja-se que diante deste modelo, não há uma relação biunívoca entre o dispositivo e a norma, sendo possível que de um mesmo dispositivo se extraia mais de uma norma, ou que se obtenha uma única norma da interpretação de diversos dispositivos determinados, ou mesmo de todo um sistema jurídico.

Quando a aludida interpretação advém de dispositivos de direitos fundamentais, fala-se então em normas de direitos fundamentais. De qualquer forma, a relação que caracteriza uma norma como fundamental dependerá sempre de um critério identificador, qual seja: uma correta fundamentação referida a direitos fundamentais (ALEXY, 2008, pp. 65/84). Essa colocação tem a vantagem de estabelecer como normas de direitos fundamentais todas aquelas que puderem ser corretamente fundamentadas nesse sentido.

A dogmática moderna, como se sabe, distingue as normas jurídicas, quanto a sua estrutura, em duas espécies: princípios e regras, sem que haja entre elas uma hierarquia, mas antes funções distintas. Tal separação, vale lembrar, não apresenta valor meramente didático, repercutindo na função exercida pela norma no sistema, na forma de sua interpretação, e na sua eficácia jurídica. No âmbito dos direitos fundamentais, a importância é ainda mais patente, envolvendo aspectos e limites de restringibilidade e âmbito de proteção.

Dentre as inúmeras teorias que tentam explicar a diferenciação entre princípios e regras jurídicas, tende a doutrina brasileira ${ }^{5}$ a seguir o marco teórico fundado nas obras de Dworkin e Alexy, e que propõe uma separação forte, estrutural ou lógica entre as espécies normativas.

Segundo as teorias componentes da citada corrente de pensamento, apresentariam princípios e regras uma distinção qualitativa (estrutural ou lógica) baseada, sobretudo, na forma de aplicação e no comportamento conflitivo de cada espécie. Assim, a qualificação de uma norma como regra ou como princípio atribuiria de antemão uma certa orientação à sua interpretação.

\footnotetext{
${ }^{5}$ Posição majoritária, mas longe de ser unânime. Em sentido crítico: ÁVILA, 2006.
} 
As origens teóricas desta corrente são geralmente atribuídas aos trabalhos de Esser e Larenz, na Alemanha, e de Pound nos EUA, que teriam reconhecido na prática judicial a utilização de padrões de justificação que fugiriam às regras legais.

Mas talvez o marco mais importante tenha sido mesmo o ataque geral de Dworkin (2007, pp. 23/35), sem dúvida influenciado pela virada kantiana ${ }^{6}$ e principalmente pela obra de Rawls (2008), ao positivismo e ao utilitarismo, em especial os modelos propostos por HART (2001). DOWRKIN critica a visão positivista de sistema jurídico fechado de regras, ressaltando a importância que os princípios e as diretrizes políticas ostentam notadamente nas decisões judiciais de casos difíceis (hard cases).

Para ele, o direito não se resumiria à coleção de normas positivadas pelo Estado, assim como a validade das proposições jurídicas não poderia se resumir a regras de competência e normas de reconhecimento (os chamados testes de pedigree de Hart) alijadas de qualquer juízo acerca de seu conteúdo. A ausência de leis ou práticas judiciais específicas, ou até mesmo a inclusão de conceitos indeterminados nas normas escritas, para a resolução do caso concreto, representaria lacunas a serem preenchidas por meio de argumentos de princípios, de modo que fosse possível o reconhecimento do direito a uma das partes, pautando-se esse reconhecimento por critérios éticos definidos, internos ao Direito, não subjetivos ou aleatórios.

De maneira original, Dworkin sustentou serem regras e princípios (em sentido amplo) espécies de normas jurídicas, ambos destinados a disciplinar condutas e fundamentar decisões judiciais. A diferença entre elas estaria no modo final de aplicação e no comportamento em hipóteses conflitivas (DWORKIN, 2007, pp. 35/63).

As regras seriam aplicáveis ao modo disjuntivo, à maneira do tudo ou nada. Ou seja, como determinam consequiências definidas e hipóteses fáticas detalhadas, ocorridos os fatos condicionantes de sua aplicação, ou a regra seria válida, e então sua conseqüência jurídica deveria ser aceita, ou não seria válida, caso em que nada contribuirá para a decisão.

Ainda segundo o autor, com relação à resolução de antinomias, as regras seriam funcionalmente importantes ou desimportantes. A aplicação de uma importaria na invalidade da

\footnotetext{
${ }^{6}$ Refere-se aqui ao movimento que, a partir da segunda metade do século XX, assentou-se na idéia de superação do formalismo positivista sem recorrer à abstração exagerada do jusnaturalismo, promovendo uma reaproximação entre Direito e Moral, notadamente com o reconhecimento da normatividade dos princípios. Por todos: BARROSO, 2008, pp. 01/48.
} 
outra: na sua exclusão do ordenamento, ou na inclusão naquela de uma cláusula de exceção. Aplicar-se-iam nesta seara os métodos clássicos de solução de antinomias (hierárquico, cronológico e de especialidade), métodos estes absolutamente insuficientes para a resolução de conflitos entre princípios.

Já o com relação aos princípios, por outro lado, sendo pontos de conexão entre Direito e Moral, concretizadores de exigências de justiça, não poderiam ser aplicados como as regras, alheios a valorações. Não definindo um suporte fático delimitado nem cominando consequiências automáticas, seriam aplicáveis a um número infinito de situações, apontando a direção a ser seguida para a solução de uma controvérsia como razões argumentativas voltadas à resolução de um caso concreto difícil, no qual haveria divergência interpretativa grave ou ausência de regras específicas, dando origem a uma nova regra, concreta, vinculada ao precedente.

Quando em conflito, hipótese em que indicariam soluções antagônicas para o caso concreto, os princípios carregariam consigo uma dimensão de peso ou importância, exigindo do intérprete uma ponderação entre os pesos relativos de cada um para a solução do caso. Do embate sairiam ambos válidos, ainda integrantes do ordenamento, por mais que a aplicação de um deles tivesse sido afastada no caso concreto. De fato, diante de outras circunstâncias fáticas, esses mesmos princípios poderiam voltar a colidir, obtendo-se um resultado diverso.

A teoria do Direito de Dworkin ainda introduziu na dogmática uma terceira espécie normativa, ainda pouco desenvolvida entre nós: a policy, que pode ser traduzida por diretriz política, ou simplesmente política pública.

De acordo com autor, os argumentos de política seriam preceitos que estabeleceriam objetivos coletivos ou metas políticas, sociais ou econômicas da sociedade que, assim como os princípios, possuiriam dimensão de peso, se abrindo à ponderação. $\mathrm{O}$ argumento aqui seria de interesse geral, fruto da maioria, embasando decisões políticas de fomento ou proteção do bem comum. O que importaria seria promover um estado de coisas desejável dentro de uma comunidade, sem que isso pudesse ser exigido do Estado por qualquer indivíduo ${ }^{7}$.

\footnotetext{
${ }^{7}$ A policy, contudo, não poderia em hipótese alguma justificar uma restrição a direitos individuais. Com efeito, os argumentos de princípio buscariam sustentar um direito individual ou de um grupo determinado, pautado na justiça ou equidade, além de argumentos contramajoriatários (uma promessa à minoria de que sua dignidade e igualdade
} 
Alexy, desenvolvendo a doutrina de Dworkin, também abraçou a distinção qualitativa entre regras e princípios. Para o autor alemão, os direitos fundamentais são vistos não como trunfos contra a maioria, mas como normas de natureza eminentemente principiológica que podem e devem ser ponderados, ou seja, restringidos, inclusive diante de um interesse coletivo.

As regras seriam mandamentos de definição (ALEXY, 2008, p. 92/93), e como tais seriam satisfeitas ou não. Imporiam, vedariam ou permitiriam condutas determinadas, apresentando razões, a princípio, definitivas. De se salientar, no entanto, que as regras, à medida que podem sofrer exceções determinadas pelo caso concreto, ofereceriam por vezes um caráter prima facie (ALEXY, 2008, p. 103/106).

Ocorre que o caráter prima facie das regras não deveria ser confundido com aquele previsto para os princípios. Na verdade, para a criação da cláusula de exceção à regra em virtude de um caso concreto, a carga argumentativa teria de demonstrar a prevalência dos princípios contrapostos tanto em relação aos princípios que dariam suporte à regra, quanto àqueles princípios chamados formais, que determinariam o cumprimento das regras editadas pelas autoridades legitimadas. No caso dos conflitos entre princípios, bastaria que a carga argumentativa fosse suficiente para ultrapassar a dos princípios opostos.

Já o conflito entre regras, tal como defendia Dworkin, se resolveria pela invalidação de uma ou pela inclusão de uma cláusula de exceção. Mas ao contrário do autor norte-americano, Alexy recusa a idéia de enumeração de exceções às regras como condição de completude destas, admitindo que as possibilidades de surgimento de exceções são infinitas.

Por sua vez, os princípios seriam preceitos que veiculariam mandamentos de otimização (ALEXY, 2008, pp. 93/103). Ordenariam a realização de um fim na maior medida possível, segundo circunstâncias fáticas e jurídicas. Assim, poderiam ser realizados em diferentes graus, apresentando razões prima facie de dever-ser, que dependeriam de outros fatores para serem aplicados

seriam respeitadas). Seriam então objetivos políticos individuais, superiores a qualquer meta coletiva, verdadeiros trunfos contra os interesses coletivos. Se fosse possível a restrição de um direito individual por um interesse coletivo qualquer, tais direitos na realidade não existiriam. Apenas os argumentos de princípio, que se fundamentariam na igual proteção do direito de outro indivíduo que seria afetado, poderiam justificar uma restrição de direitos individuais (DWORKIN, 2007, pp. 127/164). 
Com relação ao embate entre princípios, Alexy lança mão de uma Lei da Colisão, segundo a qual os princípios só entrariam em colisão diante do caso concreto, de modo que, de acordo com as circunstâncias, o interprete estabeleceria uma relação de precedência condicionada. Não haveria que se falar em precedências incondicionadas ou em abstrato de um princípio sobre o outro. As condições do caso concreto, na verdade, possuiriam um caráter duplo: ao mesmo tempo em que definem os parâmetros de uma relação de precedência entre princípios, tornam-se suporte fático de uma regra concreta, no caso, a regra de precedência, cuja consequiência jurídica seria aquela determinada pelo princípio prevalecente.

E não é só. Como forma de controle racional desta relação de precedência, para que um princípio estabeleça uma restrição a outro seria necessário que atendesse à máxima da proporcionalidade, de modo que quanto maior fosse a limitação imposta a um princípio maior deveria ser a importância atribuída ao outro princípio. A máxima da proporcionalidade decorre, segundo Alexy, do próprio caráter principiológico dos direitos fundamentais.

Dessa forma, as possibilidades fáticas que permitiriam uma restrição deveriam passar pelos juízos de adequação (se a restrição proposta seria adequada à obtenção do fim desejado) e de necessidade (se não haveria outras formas menos restritivas de se atingir o mesmo fim desejado), enquanto as possibilidades jurídicas seriam proporcionais em sentido estrito, ou seja, os princípios opostos deveriam ponderados de modo que as vantagens de se estabelecer a restrição superassem suas desvantagens ${ }^{8}$.

Partindo-se de uma distinção qualitativa entre regras e princípios, é possível designar o catálogo de normas de direitos fundamentais como um elenco misto normativo, no qual é possível a convivência harmônica entre um nível de regras e um nível de princípios (ALEXY, 2008, pp. 121/179).

Adotando-se esta visão, os direitos fundamentais devem ser considerados em sua vertente normativa, ou seja, enquanto sistema aberto de princípios e regras (GOMES CANOTILHO, 2006, pp. 1159/1189) extraídos a partir do texto constitucional por meio do processo de interpretação, e ostentando, em todo caso, pelo menos algum grau de efetividade.

\footnotetext{
${ }^{8}$ No que toca ao princípio da proporcionalidade e os critérios e problemas envolvidos no processo de ponderação de princípios, bens e interesses, vide a enorme produção de Daniel Sarmento e Ana Paula de Barcellos, exemplarmente em: SARMENTO, 2000; TORRES (Org.), 2001, p. 35; BARCELLOS, 2005; SARMENTO e GALDINO (Org.), 2006, pp. 31/44; BARROSO (Org.), 2008, p. 49.
} 
Como se vê, os direitos fundamentais possuem uma estrutura principiológica, decorrendo de seus conflitos internos, do resultado dos jogos de ponderação realizados entre os princípios contrapostos, as normas de precedência cuja natureza, não se pode olvidar, é de regra jurídica.

Da natureza eminentemente pricipiológica dos direitos fundamentais sustentada acima se pode deduzir que estes são, em regra, ponderáveis, restringíveis. Na verdade, muito embora sejam vistos hoje como um consenso mínimo imposto aos grupos políticos dominantes, seja porque representam valores essenciais da sociedade, seja porque tutelam as condições para um correto funcionamento do processo de deliberação democrática (BARCELLOS, 2006, p. 31/34), ninguém parece contestar que os direitos fundamentais não são absolutos.

Tendo em vista o seu caráter principiológico, tem-se que as normas basilares podem ceder em face de outras normas de mesma hierarquia. Porém, muito se sustenta que não se deve parar o raciocínio por aqui sob pena de flexibilizar de tal forma as normas jurídicas a ponto delas ser possível retirar-lhes toda e qualquer eficácia, ou seja, esvaziar por completo o próprio conteúdo do direito (MENDES et allii, 2008, pp. 315/316) com o estabelecimento de condicionantes descabidas ou excessivas (VIEIRA DE ANDRADE, 2010, pp. 278/279).

Com isso passamos a um outro ponto, qual seja, as balizas que devem reger as restrições impostas aos princípios constitucionais e mais, se estas restrições sofreriam, elas próprias, uma limitação (os chamados limites dos limites).

Entende-se que o discurso voltado às restrições dos direitos fundamentais deve sempre estar ligado à defesa da liberdade. Nesse sentido, os direitos fundamentais devem ser entendidos em sua extensão máxima, decorrendo a redução de sua proteção inicial apenas do embate com outros princípios de mesma hierarquia num jogo de ponderação regido por regras minimamente racionais e carentes de fundamentação constitucional.

Assim, na esteira da Teoria Externa (ALEXY, 2008, p. 276/294), não há que se falar em limites imanentes aos direitos fundamentais, que predeterminariam um âmbito de proteção ${ }^{9}$, mas apenas em um direito original, ilimitado prima facie, e, posteriormente, diante das

\footnotetext{
${ }^{9}$ Assim, por exemplo, José Carlos Vieira de Andrade, para quem não haveria duas categorias distintas, o direito e sua restrição, mas tão-somente o direito, cuja definição do âmbito de proteção já pressuporia a exclusão de certas situações fáticas (suporte fático restrito). Veja-se que tal raciocínio reduziria a função da ponderação, eis que os eventuais conflitos já seriam de plano afastados (VIEIRA DE ANDRADE, 2010, pp. 173/179).
} 
condições fáticas e jurídicas do caso concreto, em uma restrição àquele. A limitação, dessa forma, só pode surgir de uma necessidade externa de conciliação entre os direitos conflitantes, sendo imprescindível, em qualquer caso, uma fundamentação racional e constitucional ${ }^{10}$.

Para uma máxima proteção, e também para uma racionalização dos casos de nãoproteção, o suporte fático da norma de direito fundamental deve abranger todos os pressupostos materiais de incidência da norma (ALEXY, 2008, p. 321/332), mesmo nas situações mais absurdas, em que seria intuitivo a não incidência de proteção (SILVA, 2010, p. 108/113).

Adotando-se esta premissa, o conteúdo essencial dos direitos fundamentais seria o resultado das ponderações e restrições que estes sofrem em cada caso concreto, derivando disto, conseqüentemente, uma natureza normativa de regra jurídica (a regra originada da colisão) imponderável e indisponível para os Poderes Públicos.

Adere-se, portanto, à chamada Teoria Relativa do núcleo essencial que não vê neste um conjunto fixo, absoluto e intangível, mas sim como resultado da avaliação concreta de proporcionalidade que, por questões lógicas, não pode ser excessivo.

Esta posição, além de estar mais conectada com a realidade das coisas, ainda tem a vantagem de estabelecer a maior proteção possível do núcleo intangível em cada caso concreto. Ao invés de se propugnar um âmbito fixo de proteção, utopicamente válido para todos os casos em que estejam envolvidos certos direitos, permite-se uma flexibilidade para que o âmbito de proteção atinja o maior alcance possível em cada caso.

Confunde-se este núcleo essencial, sem dúvida, com o mínimo existencial enquanto garantia das condições inicias de liberdade dos homens aquém do qual não subsiste uma existência digna ${ }^{11}$, composto tanto de elementos dos direitos de liberdade clássicos (que impunham um status negativus ao Estado) quanto dos direitos de igualdade (por sua vez ensejando um status positivus libertatis).

\footnotetext{
10 Sobre o tema, imprescindível: SILVA, 2010.

11 Para Ricardo Lobo Torres, "Sem o mínimo necessário à existência cessa a possibilidade de sobrevivência do homem e desaparecem as condições iniciais da liberdade. A dignidade humana e as necessidades materiais da existência não retrocedem aquém de um mínimo, do qual nem os prisioneiros, os doentes mentais e os indigentes podem ser privados". (SOUZA NETO e SARMENTO (Org.), 2008, p. 338).
} 
Nesse sentido, o conteúdo essencial funciona como um limite às intervenções do Estado, porém não um limite maior do que a própria proporcionalidade pode oferecer (SILVA, 2010, p. $197 / 207)^{12}$.

O importante aqui é perceber que toda e qualquer restrição ao direito fundamental, seja ela veiculada por lei seja proveniente de análises hermenêuticas em consideração de outros direitos fundamentais, deverão ser constitucionalmente fundamentadas (SILVA, 2010, p. 198). Quanto maior for a relevância da preservação do direito maior também deverão ser as razões argüidas para sua restrição.

No que tange à sua eficácia, a partir da constatação de que o conteúdo essencial é regra e não goza de abstração ou generalidade nem permite a ponderação (TORRES, 2009, pp. 83/84), veiculando mandados definitivos que não podem ser mais relativizados, só resta reconhecer como modalidade padrão a eficácia simétrica ou positiva (BARCELLOS, 2002, pp. 59/79), a mais forte possível.

Se é certo que nenhum direito fundamental é absoluto, sendo todos a princípio restringíveis, também é correto que, uma vez definido o conteúdo do âmbito de proteção do direito diante do caso concreto, ou seja, após o juizo de proporcionalidade ${ }^{13}$, chega-se a um ponto definitivo, de natureza de regra, que além de não poder mais sofrer restrições deve ser objeto de forte tutela por parte do Estado.

Assim, voltando-se para o caso específico do princípio da dignidade humana, acredita-se que também este não é absoluto. E esta conclusão decorre da sua própria natureza normativa de princípio.

Contudo, com isto não se está a rechaçar por completo a construção de Alexy, quando lhe atribui uma natureza mista de regra e de princípio $(2008 \text {, p. 113/114 })^{14}$. Na verdade, o que se tem é um princípio, e como tal flexível, mas que ostenta relevância tamanha para o indivíduo e para a vida em sociedade que as razões suficientes para justificar sua restrição são peculiarmente excepcionais e igualmente relevantes.

\footnotetext{
12 Tb. GOMES CANOTILHO, 2006, pp. 1281/1283.

13 Juízo este de suma importância para a aferição da constitucionalidade da restrição. Por todos, no Brasil: PEREIRA, 2000, Cap. IV. Em Portugal, vale a nota da excelente tese de doutoramento de Jorge Reis Novais (REIS NOVAIS, 2003).

14 Tb. BARCELLOS, 2005, pp. 193/194.
} 
Por isso, evitando-se a quebra de coerência com a argumentação aqui adotada, o núcleoregra resultante da ponderação do princípio da dignidade é, em geral, mais amplo do que aqueles dos demais princípios constitucionais (SILVA, 2010, p. 200/202). A sua força vinculante, todavia, é a mesma.

Em relação ao tema central deste texto, a saber, os direitos fundamentais daqueles submetidos a medidas privativas de liberdade, pode-se concluir que a aplicação das leis penais, processuais penais e de execução das penas pelo juiz, em conjunto com a avaliação das características peculiares envolvidas no caso (de ordem objetiva e subjetiva), estruturam os limites das restrições aos direitos de liberdade do acusado, embasados em argumentos racionais de ordem constitucional e legal, delimitando assim, por outro lado, um núcleo de dignidade que não foi e não poderá mais ser afetado.

Este núcleo, que envolve direitos básicos a abstenções e a prestações, compõe, mas não coincide completamente, o que a atual doutrina penitenciarista tem chamado de estatuto jurídico do recluso, conforme se verá em tópico mais adiante.

\section{A PRÁtICA: UM BREVE PANORAMA DO SISTEMA CARCERÁRIO BRASILEIRO}

Quando se fala em sistema carcerário brasileiro, a imagem que costuma vir à mente é a da prática institucionalizada ${ }^{15}$ de violações aos Direitos Humanos. A situação vivenciada em muitas das prisões nacionais atualmente é tão caótica que o próprio presidente do Supremo Tribunal Federal, instado a se pronunciar diante do $12^{\circ}$ Congresso sobre Prevenção ao Crime e Justiça Criminal da Organização das Nações Unidas, foi obrigado a admitir, uma vez mais, a iminência do seu colapso ${ }^{16}$.

As cadeias brasileiras, não todas, mas grande parte delas, apresentam características mais de depósitos de seres humanos do que propriamente de estabelecimentos prisionais, o que

\footnotetext{
15 Para Ana Paula de Barcellos, uma prática tradicional, atual, generalizada, séria e institucionalizada (BARCELLOS, 2010).

16 "Crimes do Estado contra o povo" foram os termos estampados na reportagem do Jornal O Globo de 17 de abril de 2010.
} 
torna ainda mais grave a leniência com que o assunto vem sendo tratado pelas instâncias de poder.

O mais grave é que este estado de inércia e indiferença não se afasta do pensamento comum do povo brasileiro. De fato, o estado de violação permanente ${ }^{17}$ é conhecido e tolerado por grande parte da população, o que denota a propensão cultural à vingança e à desconsideração do criminoso enquanto ser humano.

Com isso, a questão ora abordada passa a encerrar mais do que aspectos de reivindicação perante os Poderes Públicos em prol de uma consideração mais humana dos encarcerados, é imperioso que se estabeleça também até que ponto isto seria legítimo em face do princípio democrático, em face do que as maiorias eventuais sediadas no Congresso Nacional estão autorizadas a aprovar com o aplauso de uma grande parcela da população. A isto voltaremos mais adiante.

Objetivamente, pode-se dizer que um dos problemas mais graves encontrados no atual sistema brasileiro é a superlotação, e todas as conseqüências negativas que esta traz consigo. Segundo os dados divulgados pelo Departamento Penitenciário Nacional, a população carcerária brasileira passou de pouco mais de 148.000 presos em 1995 para 361.402 em 10 anos, o que representou um crescimento de 143,91\%. De 2005 a 2009, este número saltou para cerca de 473.626 pessoas, num crescimento de $31,05 \%$ em pouco menos de 04 anos ${ }^{18}$. Hoje, o contingente de encarcerados chega a $494.237^{19}$.

\footnotetext{
${ }^{17}$ Tem sido assim desde os primórdios da história brasileira (SOUZA, 2007, Cap. 4).

${ }^{18}$ Estes são os dados consolidados pelo Sistema Nacional de Informação Penitenciária - InfoPen em 2008 e disponíveis no site do Ministério da Justiça na internet: [http://portal.mj.gov.br]..

19 Numa proporção de 258,11 presos para cada 100.000 habitantes. Para se ter um parâmetro de referência, basta indicar os índices de países como Albânia (90), Alemanha (98), Armênia (92), Áustria (100), Bósnia (53), Bulgária (127), Croácia (64), Dinamarca (62), Eslováquia (164), Eslovênia (55), Espanha (137), França (93), Grécia (83), Hungria (165), Inglaterra (140), Itália (100), Macedônia (76), Noruega (64), Países Baixos (100), Polônia (211), Portugal (134), República Tcheca (171), Romênia (199), Sérvia (73), Turquia (92). A taxa brasileira de aprisionamento se aproxima daquelas ostentadas por países de tradição repressiva, como a Estônia (330), Letônia (351) e Lituânia (260), mas também não chega aos extremos apresentados pela Rússia (595), Bielorrússia (554) e Ucrânia (415). Os dados são de 2003. DÜNKEL, Frieder; SNACKEN, Sonja. Les Prision en Europe. Collection la Justice au Quotidien. Paris: L'Harmattan, 2005, p. 12/16.
} 
Apesar da redução proporcional da taxa de crescimento anual, a insuficiência dos estabelecimentos prisionais brasileiros é evidenciada pelo déficit médio de 194.650 vagas. A superlotação, contudo, está longe de ser o único problema do sistema carcerário ${ }^{20}$.

Apesar da Constituição Federal e da Lei de Execução Penal apresentarem-se sensíveis à vulnerabilidade do preso e terem se esmerado em listar-lhes seus direitos, os relatórios de inspeção do DEPEN parecem demonstrar que nenhuma penitenciária no país as atende plenamente. Em muitos casos, verificou-se não haver sequer acesso à água, seja para higiene seja para o consumo vital. As denúncias de estruturas prediais precárias, com presença de lixo, esgoto, insetos, por vezes alagamentos, muito calor, sistemas elétricos e sanitários em colapso. A isto se acrescenta o oferecimento de comida de baixa qualidade ou em baixa quantidade ${ }^{21}$.

Não raro, a combinação de pouco arejamento e insolação, problemas com a manutenção de um padrão básico de higiene e deficiência no oferecimento de serviços de saúde culminam na proliferação de doenças ${ }^{22}$. A própria condição de promiscuidade e violência entre os internos se encarrega da disseminação de outras doenças ainda mais graves como a $\operatorname{AIDS}^{23}$.

\footnotetext{
${ }^{20}$ Embora seja um fator importante no desencadeamento de outros problemas igualmente nocivos: "Les conséquences de la surpopulation ont été maintes fois décrites dans la littérature. Des dommages sur la santé, des violences croissantes antre détenus et surveillants, un stress et un sentiment d'insécurité chez les détenus et chez les surveillants sont des effets frequents. (...) la surpopulation peut resulter en des formes de traitement inhumain et dégradant." (DÜNKEL e SNACKEN, 2005, p. 39).

${ }^{21}$ Nesse sentido, vide os relatórios de inspeção do CNPCP que são bastante descritivos.

${ }^{22}$ Em um relatório de inspeção do CNPCP de abril de 2009, Sérgio Salomão Secaira testemunha: "Atendimento médico inexiste. Flagramos presos com doenças de pele. A escabiose, em um dos casos, toma todo o tronco de um interno.”.” (p. 03). Relatório de Inspeção do CNPCP na Casa de custodia de Viana e no Presídio de Celas Metálicas de Serra, Espírito Santo, disponível em http://portal.mj.gov.br/. Acesso em 17/08/2011.

${ }^{23}$ No Espírito Santo, em caso paradigmático, presos eram mantidos em containers de metal. E esse não era em si o maior absurdo da situação. A descrição elaborada por Sérgio Salomão Shecaira, em inspeção realizada em 2009, é a seguinte: "Chegamos no início da tarde à cidade de Serra, onde estão containers que o Estado chama de presídios. O local tem capacidade para 144 presos e tinha quase quatrocentos. Quando chegamos, encontramos alguns presos encarregados de uma faxina. Vários depoimentos foram no sentido de que isso se iniciara na véspera, com o anúncio de nossa visita. Cada container tinha cerca de 40 presos. O local é absolutamente insalubre. A temperatura, no verão, passa de 45 graus, segundo vários depoimentos. Não há qualquer atividade laboral, como de resto já ocorria na CASCUVI. Não há médico. Não há advogado. Não há defensoria. Não há privacidade alguma. As visitas semanais são feitas através de uma grade farpada. São fatos comuns as crianças se cortarem ao tentar pegar na mão dos detentos por entre as grades. Não há visita íntima. Sob as celas encontramos um rio de esgoto (a manilha estava quebrada há semanas). Na água preta e fétida encontravam-se insetos, larvas, roedores, garrafas de refrigerantes, restos de marmitas, restos de comida, sujeiras de todos os tipos. A profundidade daquele rio de fezes e dejetos chegava a quarenta centímetros, aproximadamente. O cheiro era de causar náuseas. Todos nós chegamos à conclusão que nunca havíamos visto tão alto grau de degradação. Poucas vezes na história, seres humanos foram submetidos a tanto desrespeito. Vencendo a repugnância do odor, aproximamo-nos dos presos. Novas denúncias de comida podre e de violências. Encontramos um preso com um
} 
O fato que se pretende evidenciar com os tristes dados acima é que, ao fim e ao cabo, os brasileiros submetidos a penas privativas de liberdade, seja porque condenados em sentença transitada em julgado, seja porque presos preventivamente, suportam nos estabelecimentos prisionais uma violação ao núcleo essencial de seus direitos fundamentais, notadamente a dignidade humana, para além das balizas definidas legal e judicialmente.

$\mathrm{Na}$ verdade, as condições carcerárias precárias às quais estes indivíduos estão sujeitos evidenciam uma omissão estatal específica na prestação de alimentação, saúde e segurança essenciais para uma existência digna. Nunca é demais lembrar que os presos podem até ver restringida sua liberdade, em suas diversas formas, mas em hipótese alguma perdem sua dignidade, atributo incondicionado e inerente a todos os seres humanos (SARLET, 2010), em patamar de igualdade.

Se o Estado, por meio de uma Constituição Federal conformadora, é estruturado como Social e Democrático e assume a função de não apenas proteger, mas antes promover no seio da sociedade o respeito aos Direitos Humanos, não pode este mesmo Estado virar as costas para uma parcela de sua população, deixando-a ao sabor de toda a sorte de sofrimentos e violações de sua integridade física e psíquica.

E talvez o que mais salte aos olhos no caso dos reclusos que ora se analisa é que não se trata da atuação estatal voltada à proteção e à garantia de mínimo existencial de uma população livre, porém miserável, e que sofre com as falhas do sistema. Não. Trata-se de indivíduos sob a guarda permanente do Estado, cuja justificação é pautada em argumentos de prevenção geral e especial, além de promessas de ressocialização.

O fato de o Estado intervir na liberdade básica de certa parcela de cidadãos de modo a limitar seu ir e vir e sua privacidade, inserindo-a no que se convencionou chamar relação especial de sujeição, importa, sem dúvida, tanto em poderes quanto em responsabilidades muito particulares.

\section{UMA VERDADE INCONVENIENTE: O ESTATUTO JURÍDICO DO RECLUSO, A OMISSÃO ESTATAL VIOLADORA DE DIREITOS HUMANOS E A MÁXIMA SINDICABILIDADE JUDICIAL}

tiro no olho e outro com marcas de bala na barriga. Marcas de balas na parte externa dos containers são comuns. A promiscuidade impera. Violências entre presos e contra presos foram denunciadas." 
Quando se pensa em violações aos Direitos Humanos perpetradas pelo Estado, e exemplos certamente é o que não faltam, tende-se no comum dos casos a relacioná-las às barbáries das guerras, passadas e atuais, ou, num pensamento mais próximo à realidade brasileira, aos desmandos do regime militar ou, ainda, aos desvios das forças públicas policiais em sua atuação cotidiana.

Como se vê, a intuição costuma levar à identificação dos direitos fundamentais com a sua face liberal clássica de direitos de defesa, ou seja, de direitos subjetivos a uma abstenção a ser assumida pelo Estado.

Mais recentemente, por outro lado, as atenções da doutrina constitucionalista nacional e estrangeira têm se voltado à outra faceta dos direitos fundamentais, próprias de um Estado de Direitos Social e Democrático: os ditos direitos sociais fundamentais, ou direitos a prestações em sentido estrito. Nessa vertente, aqueles direitos essenciais à manutenção das condições mínimas da liberdade, e do processo democrático num segundo plano, encerrariam direitos subjetivos a prestações positivas por parte dos Poderes Públicos, integrando, junto aos direitos de defesa, o chamado mínimo existencial.

Contudo, tal lógica não se encaixa com perfeição à situação abordada neste estudo. Como visto no tópico anterior, duas das mais graves violações de Direitos Humanos dentro dos muros prisionais são a violência e a perpetuação de uma precariedade de condições de vida. Assim, para além das atuações ofensivas de agentes estatais contra os presos (como torturas, por exemplo), que em si importariam em violação a direitos de defesa liberais, releva a posição inerte, omissiva, do Estado com relação à violência perpetrada entre os presos e a degradação das condições básicas de vida dentro dos estabelecimentos prisionais ${ }^{24}$.

Neste quadro, entende-se haver direitos a prestações específicas exigíveis judicialmente do Estado, que pode ser dividido em direito a proteção e direito a prestação em sentido estrito. O primeiro configura um direito público subjetivo do titular de direitos fundamentais a que o

\footnotetext{
${ }^{24}$ Destaca-se, nesse sentido, a deficiência no oferecimento do tratamento médico, na manutenção das instalações sanitárias e acomodações, no fornecimento de alimentação, vestuário e itens de higiene pessoal, na garantia de segurança (principalmente em relação a outros detentos), enfim, na provisão das condições mínimas essenciais à sobrevivência de qualquer ser humano.
} 
Estado o proteja de intervenções de terceiros ${ }^{25}$. Já o segundo comporta o direito subjetivo ao fornecimento pelo Estado de determinados bens ou à realização de determinadas ações concretas (ALEXY, 2008, pp. 499/519).

Todavia, em que pese se tratar de direitos prestacionais, não se pode confundi-los com direitos sociais. Isso porque estes direitos decorrem da impossibilidade de seus titulares buscarem nas oportunidades da vida o seu suprimento. São, de fato, direitos às condições mínimas de uma existência digna, pressupostos que são das liberdades individuais em suas mais variadas nuances, inseridas numa relação de dependência absoluta do Estado.

No decorrer da execução da pena privativa de liberdade, o indivíduo sofre a mais duras das intervenções estatais em sua liberdade. Como qualquer restrição a direito fundamental, as penas criminais estão sujeitas a uma série de processos de ponderação que delimitarão, em cada caso, seus limites em face da esfera individual.

Uma vez encarcerada, a pessoa se insere numa relação especial de sujeição perante o Estado que, se de um lado serve de argumentos a favor de uma série de novas restrições a outros direitos fundamentais (PEREIRA, 2006, p. 603), de outro impõe ao Estado uma série de deveres específicos. Dentre estes deveres destacam-se, justamente, aqueles correspondentes aos direitos fundamentais à segurança, à proteção da vida e da integridade física, e à promoção da saúde, da educação e do trabalho.

Note-se que o recluso encontra-se em ambiente de tamanha intervenção que sua própria sobrevivência não depende mais de si ou seus esforços, mas sim da atuação estatal (tome-se como exemplo o próprio fornecimento de alimentação, a infraestrutura sanitária, de higiene básica, de saúde e, inclusive, de segurança). Nesse cenário, a realidade do sistema prisional brasileiro, e suas graves omissões, devem ser entendidas como violações estatais aos direitos humanos enquanto direitos a prestações definitivamente vinculantes ${ }^{26}$.

25 "Seria, então, possível falar de uma violação a direito fundamental por parte do Estado, que surge quando ele não cumpre de forma suficiente seu dever de proteção." (ALEXY, 2008, p. 453).

${ }^{26}$ Quanto à garantia definitiva de um direito a prestação, apesar de se referir apenas aos direitos sociais fundamentais (prestacionais em sentido estrito), afirma Alexy: “Uma posição no âmbito dos direitos a prestações tem que ser vista como definitivamente garantida se (1) o princípio da liberdade fática a exigir de forma premente e se (2) o princípio da separação de poderes e o princípio democrático (que inclui a competência orçamentária do parlamento) bem como (3) os princípios materiais colidentes (especialmente aqueles que dizem respeito à liberdade jurídica de outrem) forem afetados em uma medida relativamente pequena pela garantia constitucional da posição prestacional e pelas decisões do tribunal constitucional que a levarem em consideração. Essas 
Diante da necessidade de se reafirmar a dimensão humana dos presos a doutrina tem se dedicado à execução penal, no sentido de definir, a partir de um princípio geral de humanidade das penas, um estatuto jurídico do recluso capaz de converter o indivíduo de objeto a sujeito de direitos.

A necessidade de elaboração dogmática de um estatuto especial ${ }^{27}$, exclusivamente para os presos, como visto, surge da constatação de que estes participam de uma relação muito própria e muito próxima à Administração Pública que não implica os mesmos direitos e deveres em geral exigidos de cidadãos e do Estado.

A esta situação peculiar, embora a expressão já não possa denotar o seu significado original, convencionou-se chamar de relações especiais de sujeição ${ }^{28}$. Em sua origem, aos presos, funcionários públicos, militares e alunos da rede pública de ensino se costumava exigir um dever de obediência bem superior àquele exigido dos particulares em geral, tendo em vista a necessidade de manutenção da disciplina, da ordem e da eficiência de determinado órgão público (VIEIRA DE ANDRADE, 2010, p. 294). Disso se deduzia a impossibilidade de invocação de direitos e garantias fundamentais pelos submetidos em face do Estado, criando-se, desse modo, um âmbito infenso aos direitos fundamentais, um campo literalmente ajurídico.

Ocorre que no longo, lento e complexo processo de superação desse modelo e de consolidação dos direitos dos reclusos dois momentos se mostraram especialmente marcantes (RODRIGUES, 2002, p. 69): o reconhecimento da juridicidade da relação (exigência de legalidade), e o reconhecimento das garantias constitucionais.

Em primeiro lugar, a progressiva afirmação histórica do Estado de Direito, notadamente naquilo que disciplina e limita o poder estatal em face do cidadão, transformou aquelas relações de poder em relações propriamente jurídicas, com direitos e deveres recíprocos entre administradores e administrados (RODRIGUES, 2000, p. 39).

condições são necessariamente satisfeitas no caso dos direitos fundamentais sociais mínimos, ou seja, por exemplo, pelos direitos a um mínimo existencial, a uma moradia simples, à educação fundamental e média, à educação profissionalizante e a um patamar mínimo de assistência médica." (ALEXY, 2008, p. 512).

27 Em contraposição ao estatuto geral dos cidadãos.

28 Sobre as diversas designações e suas críticas: PEREIRA, 2000, pp. 388/389. 
Noutro momento, com o reconhecimento da efetividade das normas da Constituição, não haveria campo que estivesse imune às suas disposições ${ }^{29}$. A bem da verdade, a valorização dos direitos dos detentos é reflexo de um movimento maior de defesa dos direitos humanos, iniciado com as Declarações Históricas do final do século XVIII ${ }^{30}$ e que culminou na Declaração Universal dos Direitos do Homem, de 1948, e os pactos a ela correlatos ${ }^{31}$.

Em meio a esta notável marcha do pensamento moderno a Comissão Internacional Penal e Penitenciária elaborou, em 1929, e reviu em 1933, um conjunto de regras mínimas para o tratamento dispensado aos presos que deveria ser adotado pelos países integrantes da então Liga das Nações. Mais tarde, as Regras Mínimas para o Tratamento dos Reclusos ${ }^{32}$ viria a ser a dotada pelo $1^{\circ}$ Congresso da Organização das Nações Unidas sobre a Prevenção do Crime e o Tratamento dos Delinqüentes e recomendada aos países por Resolução do Conselho Econômico e Social da ONU, em 1957.

$\mathrm{Na}$ verdade, um dos postulados mais valiosos da dignidade humana é justamente o de que todos os seres humanos, seja quem for, seja o que tenha feito, gozam de direitos fundamentais. A única consequiência da sua inserção numa relação especial de sujeição só pode ser a averiguação de motivos maiores a justificar jurídica e racionalmente uma maior restrição

\footnotetext{
${ }^{29}$ Com relação à situação específica dos presos, importante papel teve a decisão do Tribunal Constitucional da Alemanha, em 1972, que estabeleceu como pressuposto para toda e qualquer restrição a direitos fundamentais, inclusive dos reclusos, devem ser justificadas e aplicadas apenas enquanto necessárias à manutenção da ordem e da segurança no estabelecimento prisional. (BVerfGE 33, I, 1972). MUÑAGORRI LAGUÍA at al (Ed.), 2000, pp. $39 / 40$.

${ }^{30}$ A Declaração de Direitos da Virgínia, de 1776, a Declaração de Independência dos EUA, do mesmo ano, e a Declaração dos Direitos do Homem e do Cidadão, de 1789.

${ }^{31}$ Notadamente o Pacto de Direitos Civis e Políticos, o Pacto de Direitos Econômicos, Sociais e Culturais, a Convenção contra a Tortura e outros Tratamentos ou Penas Desumanos ou Degradantes, e, no caso das Américas, a Convenção Interamericana de Direitos do Homem.

${ }^{32}$ A essas regras, somam-se ainda outras especificadas na Resolução n ${ }^{\circ}$ 14, do Conselho Nacional de Política Criminal e Penitenciária, de 1994, que dispõe sobre regras mínimas para o tratamento do preso no Brasil, das quais destaco, aqui, as seguintes: 1) Quando da utilização de dormitórios coletivos, estes deverão ser ocupados por presos cuidadosamente selecionados e reconhecidos como aptos a serem alojados nessas condições; 2) O preso disporá de cama individual provida de roupas, mantidas e mudadas correta e regularmente, a fim de assegurar condições básicas de limpeza e conforto; 3) Os locais destinados aos presos deverão satisfazer as exigências de higiene, de acordo com o clima, particularmente no que se refere à superfície mínima, colume de ar, calefação e ventilação; 4) $\mathrm{O}$ local onde os presos desenvolvem suas atividades deverá apresentar, dentre outras exigências, janelas amplas, dispostas de maneira a possibilitar a circulação de ar fresco, instalações sanitárias adequadas para que o preso possa satisfazer suas necessidades naturais de forma higiênica e decente, preservada sua privacidade, e instalações condizentes para que o preso possa tomar banho à temperatura adequada ao clima e com freqüência que exigem os princípios básicos de higiene.
} 
aos seus direitos (PEREIRA, 2000, pp. 426/429) ${ }^{33}$. Os deveres especiais de obediência, disciplina e ordem só podem ser levados em consideração enquanto razões hermenêuticas suficientemente fortes para sustentar intervenções mais invasivas na esfera de liberdades do indivíduo.

No caso brasileiro não se pode falar nem em inércia do Poder Legislativo no que concerne à regulamentação legal do sistema carcerário. Pelo contrário. O artigo 38, do Código Penal, e a Lei de Execução Penal (Lei n ${ }^{\circ} 7.210 / 84$ ), em especial seus artigos $3^{\circ}, 40$ e 41 (além dos artigos 85, 88, 91 e 92, mais específicos) formam um conjunto normativo notável no que toca à consideração humana dos encarcerados. O sistema legal construído se coaduna, inclusive, com as garantias constitucionais impositivas constantes do artigo $5^{\circ}$, incisos III e XLVII, XLVIII e XLIX, da Constituição Federal.

O que se infere, portanto, é o absoluto desrespeito à lei e à Constituição da República na prática, um distanciamento evidente, reprovável e nocivo entre o âmbito normativo e a realidade fática. A isto se poderia responder com a reafirmação da efetividade das normas constitucionais (BARROSO, 2009, pp. 73/86) e com o recurso ao Poder Judiciário para se pleitear à restauração da juridicidade ${ }^{34}$.

Ocorre que dentre os motivos em geral elencados para justificar as carências gerais do sistema prisional, e a abstenção dos juízes e tribunais em determinar aos Gestores Públicos uma ação efetiva ${ }^{35}$ é a escassez de recursos públicos, na linha da Teoria da Reserva do Possível.

Afirma-se que, diante de um cenário de recursos limitados e demandas ilimitadas, caberia ao Poder Executivo, com a expertise de gestão que lhe é própria, elaborar da melhor forma possível as políticas públicas na escolha dramática de destinação dos recursos públicos. A atuação do Estado dependeria sempre do contexto fático, da realidade, das possibilidades

\footnotetext{
33 Contrária a qualquer utilidade prática para o conceito: WIMMER, Miriam. As Relações de Sujeição Especial na Administração Pública. in Revista Direito Público, n 18, out/2007, p. 52.

${ }^{34}$ Não se tem dúvidas quanto à vinculação da Administração Pública, mais que à lei, à Constituição. Sobre o assunto, o trabalho primoroso de Gustavo Binenbojm (BINENBOJM, 2006).

${ }^{35}$ Há felizes exceções à regra de não intervenção judicial, em especial no Tribunal de Justiça do Estado do Rio Grande do Sul, como por exemplo: AI em ACP no 70034484964, Primeira Câmara Cível, Rel. Des. Carlos Roberto Lofego Canibal, DJ de 25/06/2010; AE nº 70032638751, Sexta Câmara Criminal, Rel. Des. Mário Rocha Lopes Filho, DJ de 27/01/2010; MS nº 70030274369, Rel. Des. Isabel de Borba Lucas, DJ de 20/08/2009; MS n 70022934871 , Rel. Des. João Batista Marques Tovo, DJ de 14/05/2008.
} 
orçamentárias. Todavia, pensamos que tal argumento, embora fundamentado, não se sustenta em todas as situações.

Em primeiro lugar, com vistas a solucionar este problema de cunho econômico, foi criado em 1994 (Lei Complementar n 79), o Fundo Penitenciário Nacional com a finalidade de proporcionar recursos e meios para financiar e apoiar as atividades de modernização e aprimoramento do sistema penitenciário.

Essencialmente, o Fundo é constituído com recursos que possuem origem nas dotações orçamentárias da União, custas judiciais recolhidas em favor da União, arrecadação dos concursos de prognósticos, recursos confiscados ou provenientes da alienação dos bens perdidos em favor da União Federal, multas decorrentes de sentenças penais condenatórias com trânsito em julgado, fianças quebradas ou perdidas, e rendimentos decorrentes da aplicação de seu patrimônio. Os recursos consignados ao FUNPEN são (ou deveriam ser) aplicados em construção, reforma, ampliação de estabelecimentos penais; formação, aperfeiçoamento e especialização do serviço penitenciário; aquisição de material permanente, equipamentos e veículos especializados imprescindíveis ao funcionamento dos estabelecimentos penais; formação educacional e cultural do preso e do internado; e em programas de assistência jurídica aos presos e internados carentes.

Não obstante a louvável iniciativa, boa parte dos recursos vinculados ao FUNPEN não estão sendo efetivamente utilizados pelos entes federados ${ }^{36}$, muitas vezes em razão da relutância dos Municípios em aceitar a construção de novas prisões dentro de seus limites territoriais (BARCELLOS, 2010).

Como se vê, não parece ser a carência de recursos uma razão suficientemente fundada para que se afaste de plano a intervenção estatal nos estabelecimentos prisionais a fim de adequá-los às exigências legais e constitucionais.

Por outro lado, ainda que a carência de verbas fosse real, não se trata aqui de políticas públicas afetas apenas aos gestores democraticamente legitimados, cuja sindicabilidade judicial esbarraria em exigências de separação de Poderes e se limitaria a uma análise de

\footnotetext{
${ }^{36}$ O acompanhamento dos repasses através de Convênios pode ser feito pelo site do Ministério da Justiça. Os últimos números são referentes ao ano de 2008.
} 
proporcionalidade $^{37}$ e razoabilidade da decisão assumida soberanamente pelos Poderes Legislativo e Executivo.

A doutrina da reserva do possível surgiu na Alemanha como um conceito aplicado aos direitos sociais, no sentido de que as prestações sociais se legitimam pelo princípio majoritário de concessão discricionária do legislador (TORRES, 2009, p. 103/105). Não se questiona que a decisão última acerca da implementação dos direitos sociais seja de primazia do legislador (TORRES, 2006, pp. 786/790), eis que voltada a imperativos de justiça.

Porém, nem tudo o que se afirma para os direitos sociais são aplicáveis a todos os direitos prestacionais, e é isso que não se pode perder de vista. Não se pode afastar a teoria de suas bases legitimadoras.

Ora, já de plano salta aos olhos que o problema de alocação e disponibilidade financeira dos recursos públicos diz respeito à implementação de todo e qualquer direito, seja ele de proteção, de prestação ou de participação política. Afinal, a garantia e promoção de direitos sempre demandará mobilização da estrutura estatal e dispêndio de verbas (HOLMES e SUSTEIN, 1999), não sendo esta uma característica exclusiva dos direitos sociais.

Mas isto por si só não é suficiente à aposição da reserva do possível como argumentação genérica a justificar a omissão do Estado na proteção e promoção dos direitos fundamentais de seus cidadãos ${ }^{38}$. Não. Há certos direitos que, diante de sua imprescindibilidade para o indivíduo e para a própria convivência social, não podem depender da boa vontade da maioria ${ }^{39}$.

Estes direitos, pensamos, compõem o mínimo existencial e como tal estão infensos à cláusula de reserva financeira (TORRES, 2009, pp. 105/106) ${ }^{40}$. Trata-se do núcleo essencial dos direitos fundamentais consagradores das condições mínimas de liberdade, entendida esta como garantia da esfera privada de desenvolvimento que cada homem possui. O status positivus

\footnotetext{
37 Como parece propor Gustavo Amaral (TORRES, Ricardo Lobo (Org.), 2001, pp. 116/118).

38 "A força do princípio da competência orçamentária do legislador não é ilimitada. Ele não é um princípio absoluto. Direitos individuais podem ter peso maior que razões político-financeiras." (ALEXY, 2008, p. 450).

${ }^{39}$ Nas palavras de Alexy: "Em virtude de normas de direitos fundamentais, todos encontram-se em posições de direitos a prestações que são, do ponto de vista do direito constitucional, tão importantes que a decisão sobre elas não possa ser simplesmente deixada para a maioria parlamentar simples." (ALEXY, 2008, p. 450).

40 Narra a doutrina que, nos EUA, foi imprescindível à afirmação dos direitos fundamentais a manipulação de verbas e alocação de recursos pelo próprio Poder Judiciário por meio do mandado de injunção, principalmente no caso de implementação dos direitos dos negros e dos presos (TORRES, 2009, p. 101).
} 
libertatis que consagra abrange tanto liberdade de (não intervenção clássica) quanto a liberdade para (que envolve as condições sociais de liberdade).

Não se está a afastar a o argumento orçamentário da pauta. A reserva do possível (no sentido daquilo que pode o indivíduo razoavelmente exigir da sociedade) é um argumento forte que deve ser considerado no momento de delimitação das restrições ao direito fundamental, mas incapaz de eliminá-lo. No caso em questão, servirá para justificar a modicidade de certas estruturas prisionais, porém jamais teria força suficiente para fundamentar as condições que hoje não importam em dissabores e sim sofrimentos degradantes.

Se por um lado esta concepção limita a normatividade dos direitos sociais situados fora do mínimo existencial, e, portanto, não relacionados diretamente com as liberdades, por outro confere o máximo de normatividade aos direitos constantes deste núcleo (TORRES, 2001, p. $264)^{41}$. E, sem dúvidas, o estatuto do recluso se encontra neste núcleo quando toca o direito à vida, à integridade física, à segurança, à saúde, à educação e ao trabalho (no sentido de oferecimento de oportunidades de educação e trabalho).

Por certo, o caso em questão encerra argumentos contramajoritários preponderantes que sustentam direitos públicos subjetivos às prestações positivas do Estado, independentemente da disponibilidade de recursos públicos destinados especificamente à política carcerária. Não há que se falar em reserva do possível quando está em jogo o mínimo de dignidade daqueles a quem o próprio Estado, ao limitar a liberdade inerente ao ser humano, assume os deveres inafastáveis da tutela.

Nas palavras de REIS NOVAIS: "Em qualquer caso, nos direitos de liberdade, ao contrario dos direitos sociais, os deveres que incubem ao Estado são independentes de quaisquer disponibilidades financeiras ou materiais." (REIS NOVAIS, 2003, p. 135).

Assim, não se tratando propriamente de políticas públicas, mas de garantias mínimas de dignidade humana, parece plenamente viável a demanda judicial de natureza coletiva com vistas à imediata adequação dos estabelecimentos prisionais aos padrões legais.

Aliás, nos EUA a afirmação dos direitos fundamentais demandou a utilização do mandado de injunção para a alocação de verbas constantes da lei orçamentária pelo próprio

41 Assim também em BARROSO (Org.), 2008, pp. 308/315. 
Poder Judiciário $^{42}$, justamente no que diz respeito à implementação dos direitos dos presos (TORRES, 2009, p. 101) $)^{43}$.

\section{CONCLUSÃO}

Assim, chega-se ao ponto de convergência almejado com este estudo. Os encarcerados, em virtude de sua situação de peculiar vulnerabilidade frente ao Estado e de baixa capacidade de mobilização ${ }^{44}$, ostentam um estatuto jurídico com direitos e deveres específicos, mas que, dentre os direitos se destacam aqueles negativos - direitos a abstenções do Estado - e positivos - direitos a prestações por parte do Estado - (RODRIGUES, 2002, p. 86/102).

O estatuto ao qual se faz referência é resultado da ponderação realizada pelos legisladores e juízes no processo de imposição e execução da pena criminal, enquanto restrição aos direitos fundamentais do recluso. Sendo assim, as normas constitucionais e legais aplicáveis ao regime carcerário, e a sentença criminal no caso concreto, delineiam um campo de direitos elementares que permanecem com os reclusos e que não podem ser violados.

Aqueles direitos elencados pela Lei de Execução Penal (Lei $n^{\circ} 7.210 / 84$ ) e que se vinculam à garantia das condições mínimas de uma existência digna pertencem ao núcleo essencial dos direitos fundamentais, cuja natureza normativa de regra impõe o respeito pelas autoridades públicas sob pena de serem exigidos por meio de recurso ao Judiciário, independentemente da disponibilização de verbas públicas para aplicação àquela situação.

\footnotetext{
${ }^{42}$ É certo que a adoção do mandado de injunção, no Brasil, para esse fim, reclamaria uma alteração radical na função que o Supremo Tribunal Federal tem atribuído ao mesmo. Com criticas à escassa eficácia do instituto no modelo brasileiro: BARROSO, 2006, pp. 112/132.

${ }^{43}$ Na síntese de Heleno Fragoso: "Nos Estados Unidos os tribunais tradicionalmente adotaram uma política de não interferência na administração penitenciária (hands off), situando-a fora do controle judicial. (...). Uma decisão importante da Corte Suprema, em 1961 (Monroe vs. Pape), veio tornar possível questionar, em escala mais ampla, por via judicial, a situação das prisões, e os tribunais começaram a receber demandas sobre regulamentos arbitrários, superpopulação, condições desumanas de vida, falta de assistência médica, ausência de facilidades recreacionais e educacionais. A partir do início dos anos 70 a doutrina do hands off é abandonada, passando-se a entender que a interferência judicial era possível em casos de comportamento claramente arbitrário ou abusivo." FRAGOSO, Heleno Claudio. A Perda da Liberdade: Os direitos dos presos. Artigo disponível em http://www.fragoso.com.br/cgi-bin/heleno_artigos/arquivo71.pdf. Acesso em 21 de janeiro de 2011.

${ }^{44}$ Em tempo, não se pode esquecer que os detentos formam uma minoria com seríssimos déficits de representatividade, seja por reunirem caracteres de rejeição popular, seja por pertencerem a um conjunto relativamente restrito da população, ou ainda por não poderem votar, eis que seus direitos políticos são suspensos em razão da condenação criminal por disposição constitucional (art. 15, III, da Constituição Federal).
} 
Não se pretende aqui a determinação pelo Judiciário desta ou daquela medida concreta, mas de determinação de que medidas sejam adotadas em caráter emergencial para a resolução imediata dos problemas de infraestrutura, superlotação ${ }^{45}$ e serviços. Pensamos ser medidas possíveis: a interdição de estabelecimentos prisionais; a cominação de multas coercitivas contra a fazenda pública enquanto não realizadas, após um prazo razoável, ou as reformas necessárias à adequação dos atuais presídios em funcionamento ou a construção de novos; a transferência compulsória de presos; a adoção de medidas emergenciais para a redução da população carcerária, como a encampação de mecanismos de suspensão da pena ou de medidas alternativas de cumprimento das mesmas, atendidos critérios objetivos mínimos a serem construídos pela jurisprudência e também de razoabilidade ${ }^{46}$.

É certo que a proposta defendida neste estudo não tem a pretensão de se tornar solução definitiva para o problema do cárcere brasileiro. Não se ignora que a questão envolve revisões maiores, de cunho penal, processo penal e político-criminal. O que se busca, no entanto, é justamente cobrar dos gestores públicos estas revisões, de forma urgente, que se coloque em pauta o sistema carcerário como ponto prioritário.

O que não pode continuar é a indiferença estatal à situação calamitosa de grande parte dos presídios brasileiros. Trata-se do núcleo essencial dos direitos fundamentais de cerca de 500.000 pessoas, reiteradamente violado, que numa estrutura de regra não sofre mais ponderações de qualquer sorte, inclusive em virtude de razões orçamentárias.

\section{REFERÊNCIAS}

ALEXY, Robert. A Teoria dos Direitos Fundamentais. Trad. Virgílio Afonso da Silva. São Paulo: Martins Fontes, 2008.

\footnotetext{
${ }^{45}$ Vale ressaltar no campo de amenização dos problemas de superlotação as iniciativas doutrinárias no sentido da adoção, no Brasil, dos mecanismos de monitoramento eletrônico de presos. Recentemente, estas vozes se fizeram ouvidas (parcialmente) com a promulgação da Lei $n^{\circ} 12.258 / 10$. Embora pretenda inserir no ordenamento jurídico aquele instrumento, o excesso de vetos presidenciais retirou daquela norma boa parte de suas vantagens iniciais. Sobre o monitoramento eletrônico, de suas origens ao projeto que deu origem a atual lei (JAPIASSÚ e MACEDO, 2008, p. 26).

46 O Superior Tribunal de Justiça tem aceitado a colocação em prisão domiciliar de condenados a penas de prisão em regime aberto quando não há vagas disponíveis para o cumprimento nestas condições, sendo certo que o agravamento da pena em virtude de tal carência de vagas é, por óbvio, inadmissível.
} 
. Conceito e Validade do Direito. Trad. Gercélia Batista de Oliveira Mendes. São

Paulo: Martins Fontes, 2009.

ÁVILA, Humberto B. Teoria dos Princípios: da definição à aplicação dos princípios jurídicos. 5 ed. São Paulo: Malheiros, 2006.

BARCELloS, Ana Paula de. Ponderação, Racionalidade e Atividade Jurisdicional. Rio de Janeiro: Renovar, 2005.

- A Eficácia Jurídica dos Princípios Constitucionais: O Princípio da Dignidade da Pessoa Humana. Rio de Janeiro: Renovar, 2002.

- Urban violence, prison conditions and human dignity. Seminario en Latinoamerica de Teoría Constitucional y Política, Santiago, Chile, 2010. Disponível em www.law.yale.edu (Acessado em 10/04/2011).

BARROSO, Luís Roberto. O Direito Constitucional e a Efetividade de suas Normas: Limites e Possibilidades da Constituição Brasileira. $9^{a}$ ed. Rio de Janeiro: Renovar, 2009.

. (Org.). A Nova Interpretação Constitucional: Ponderação, direitos fundamentais e relações privadas. $3^{a}$ ed. Rio de Janeiro: Renovar, 2008.

O Controle de Constitucionalidade no Direito Brasileiro. 2 ed. São Paulo:

Saraiva, 2006

BINENBOJM, Gustavo. Uma Teoria do Direito Administrativo: Direitos Fundamentais, Democracia e Constitucionalização. Rio de Janeiro: Renovar, 2006.

DÜNKEL, Frieder; SNACKEN, Sonja. Les Prision en Europe. Collection la Justice au Quotidien. Paris: L'Harmattan, 2005.

DWORKIN, Ronald. Levando os direitos a sério. Trad. Nelson Boeira. $6^{\mathrm{a}}$ ed. São Paulo: Martins Fontes, 2007. 
FERRAJOLI, Luigi. Derecho y Razón: Teoría del garantismo penal. Madrid: Trotta, 1995.

FOUCAULT, Michel. Vigiar e Punir: Nascimento da prisão. Trad. Raquel Ramalhete. 20 ed. Petrópolis: Vozes, 1999.

FRAGOSO, Heleno Claudio. A Perda da Liberdade: Os direitos dos presos. Artigo disponível em http://www.fragoso.com.br/cgi-bin/heleno_artigos/arquivo71.pdf. (Acessado em 21 de janeiro de 2011).

GOMES CANOTOLHO, José Joaquim. Direito Constitucional e Teoria da Constituição. $7^{\mathrm{a}}$ ed. Coimbra: Almedina, 2006.

HART, Herbert L. A. O Conceito de Direito. 3. ed. Trad. A. Ribeiro Mendes. Lisboa: Fundação Calouste Gulbenkian, 2001.

HESSE, Konrad. A Força Normativa da Constituição. Trad. Gilmar Ferreira Mendes. Porto Alegre: Sergio Antonio Fabris, 1991.

HOLMES, Stephen; SUNSTEIN, Cass R. The Cost of Rights: Why Liberty Depends on Taxes. New York-London: W. W. Norton \& Company, 1999.

JAPIASSÚ, Carlos Eduardo Adriano; MACEDO, Celina Maria. O Brasil e o Monitoramento Eletrônico. in Monitoramento eletrônico uma alternativa à prisão? Experiências internacionais e perspectivas no Brasil, Brasília: CNPCP, 2008, p. 26.

JUNQUEIRA, Gustavo Octaviano Diniz; FULLER, Paulo Henrique Aranda. Legislação Penal Especial. Vol. 1. 2a ed. São Paulo: Saraiva, 2010.

KELSEN, Hans. Teoria Pura do Direito. Trad. João Baptista Machado. 6 ed. São Paulo: Martins Fontes, 1999.

KRIESMAN, N. H. Perspectiva Penitenciária. Pamplona: Analecta, 2005. 
MENDES, Gilmar Ferreira; et allii. Curso de Direito Constitucional. $3^{\mathrm{a}}$ ed. São Paulo: Saraiva - IDP, 2008.

PEREIRA, Jane Reis Gonçalves. Interpretação Constitucional e Direitos Fundamentais: Uma contribuição ao estudo das restrições aos direitos fundamentais na perspectiva da teoria dos princípios. Rio de Janeiro: Renovar, 2000.

RAWLS, John. Uma Teoria da Justiça. $2^{\text {a }}$ ed. Trad. Jussara Simões. São Paulo: Martins Fontes, 2008.

REIS NOVAIS, Jorge. As Restrições aos Direitos Fundamentais Não Expressamente Autorizadas pela Constituição. Coimbra: Coimbra Editora, 2003.

RODRIGUES, Anabela Miranda. Derechos de los Reclusos y Control Jurisdicional de la Ejecución de la Pena de Prisión. in Muñagorri Laguía, Ignacio; Rodrigues, Anabela Maria Pinto de Miranda; Rivera Beiras, Iñaki (Ed.). Legalidad Constitucional y Relaciones Penitenciarias de Especial Sujeción. Barcelona: M.J.Bosch, 2000, p. 35.

Novo Olhar sobre a Questão Penitenciária. 2a ed. Coimbra: Coimbra Editora, 2002.

SARLET, Ingo Wolfgang. Dignidade da Pessoa Humana e Direitos Fundamentais na Constituição de 1988. $8^{\text {a }}$ ed. Porto Alegre: Livraria do Advogado, 2010.

SARMENTO, Daniel. A Ponderação de Interesses na Constituição Federal. Rio de Janeiro: Lumem Juris, 2000

; GALDINO, Flavio (Org.). Direitos Fundamentais: Estudos em homenagem ao Professor Ricardo Lobo Torres. Rio de Janeiro: Renovar, 2006.

SILVA, Luís Virgílio Afonso. Direitos Fundamentais - Conteúdo essencial, Restrições e Eficácia. $2^{a}$ ed. São Paulo: Malheiros, 2010. 
SOUZA, Artur de Brito Gueiros. Presos Estrangeiros no Brasil: Aspectos jurídicos e criminológicos. Rio de Janeiro: Lumen Juris, 2007.

TONRY, Michael; PETERSILIA, Joan. American Prisons at the Beginning of the Twenty-First Century. in TONRY, Michael (Ed.). Crime and Justice: A Review of Research. Vol. 26. Chicago-London: The University of Chicago Press, 1999.

TORRES, Ricardo Lobo (Org.). Teoria dos Direitos Fundamentais. $2^{\mathrm{a}}$ ed. Rio de Janeiro: Renovar, 2001.

(Org.). Legitimação dos Direitos Humanos. $2^{\mathrm{a}}$ ed. Rio de Janeiro: Renovar, 2007.

. O mínimo existencial como conteúdo essencial dos direitos fundamentais. in SOUZA NETO, Cláudio Pereira de; SARMENTO, Daniel. (Org.). Direitos Sociais: Fundamentos, Judicialização e Direitos Sociais em Espécie. Rio de Janeiro: Lumen Juris, 2008, p. 336.

. O Direito ao Mínimo Existencial. Rio de Janeiro: Renovar, 2009.

VIEIRA DE ANDRADE, José Carlos. Direitos fundamentais na Constituição portuguesa de 1976. $4^{a}$ ed. Coimbra: Almedina, 2010.

WIMMER, Miriam. As Relações de Sujeição Especial na Administração Pública. in Revista Direito Público, $\mathrm{n}^{\circ} 18$, out/2007, p. 31. 